\title{
Optimized output-based input shaping for control of single-link flexible manipulator using linear matrix inequality
}

\author{
Nura Musa Tahir ${ }^{1}$, Mustapha Muhammad ${ }^{2}$, Bashir Bala Muhammad ${ }^{3}$, Haliru Liman ${ }^{4}$, \\ Aminu Yahaya Zimit ${ }^{5}$, Auwal Shehu Tijjani ${ }^{6}$ \\ ${ }^{1}$ Department of Mechatronics and System Engineering, Abubakar Tafawa Balewa University, Nigeria \\ ${ }^{4}$ Department of Electrical and Electronics Engineering, Abubakar Tafawa Balewa University, Nigeria \\ ${ }^{2}$ Department of Mechatronics Engineering, Bayero University, Nigeria \\ ${ }^{3}$ School of Mechanical Engineering, Northwestern Polytechnical University, Xi'an China \\ ${ }^{6}$ Department of Electrical and Computer Engineering, Baze University, Nigeria \\ ${ }^{5}$ Department of Mechanical Engineering Technology, Hafar Albatin University, Saudi Arabia
}

\begin{tabular}{l}
\hline Article Info \\
\hline Article history: \\
Received Feb 2, 2020 \\
Revised Apr 4, 2020 \\
Accepted Apr 18, 2020 \\
\hline Keywords: \\
Command shaping \\
Flexible manipulators \\
Hybrid \\
Linear matrix inequality \\
Payloads \\
Robust \\
Single link \\
Suppression \\
\hline
\end{tabular}

\begin{abstract}
Precise hub angle positioning due to tip deflections, flexible motions and under various payloads is enormous tasks in the control of single-link flexible manipulators. In this paper, output-based command shaping (OBCS) was designed using the system output for tip deflections and residuals vibrations suppression, and this was incorporated with a linear matrix inequality (LMI) closed-loop control scheme for precise hub angle positioning. The robustness of the hybrid control scheme was tested by changing the payloads from $0 \mathrm{~g}$ to $30 \mathrm{~g}$, and $50 \mathrm{~g}$. Simulation results showed that endpoint residuals vibrations and tip deflections due to flexible motions were suppressed and hence precise hub angle positioning under various payloads was achieved. Integral absolute error (IAE), Integral square error (ISE) and Time response analysis (TRA) were used as the performance indexes. Hence, the hybrid control scheme is simple and robust.
\end{abstract}

Copyright $\odot 2020$ Institute of Advanced Engineering and Science. All rights reserved.

\section{Corresponding Author:}

Nura Musa Tahir,

Department of Mechatronics and System Engineering,

Abubakar Tafawa Balewa University (ATBU),

Bauchi, Nigeria.

Email: nuratahir85@gmail.com

\section{INTRODUCTION}

The flexible manipulator is an equipment used in transporting objects from one position to another, which find applications in automotive industries, space exploration, nuclear plants, and aerospace. The flexible arm comprises of multiple parts that are controlled electronically in performing various industrial tasks such as welding and assembling of parts [1-4]. Flexible manipulators are categorized into flexible and rigid body manipulators. Compare to rigid body manipulators, flexible manipulators are safer and more economical, and they have high speed, less mass, and less energy consumption [5]. Recently, the control of flexible manipulators has attracted the attention of many researchers. Several control algorithms such as feedforward and feedback control methods were proposed and employed in the control of a singlelink flexible manipulator. The feedforward control method is applied for residual vibration control while the manipulator coordinate is mostly controlled using the feedback control approach. modern control strategies such as robust and adaptive control methods were employed to control the single-link flexible manipulators $[1,4,6]$. Furthermore, studies [6-9] suggested zero vibration (ZV), zero vibration derivatives (ZVD), and zero vibration derivative derivatives (ZVDD) to suppress residual vibrations and oscillations. In [10], a hybrid control schemes for tip deflection suppression and hub angle tracking was proposed. Where the 
input command filter was designed to suppress tip deflection and was incorporated with LQR for tracking control. Researchers [11] proposed proportional integral derivative (PID) as feedback control for rigid body motion control of single-link flexible manipulator. A hybrid output based input shaping control scheme for vibration and position control of a single-link flexible manipulator was proposed in [12], an output-based filter was designed to reduce tip deflection while the linear quadric regulator (LQR) controller and PID controller were incorporated for precise hub angle positioning of the single-link flexible manipulator.

Besides, other researchers' have proposed various hybrid control schemes for flexible manipulators. The adaptive interactive proportional-derivative (PD) control approach for active vibration and position control of the pneumatic drive was investigated in [13], The system's rigid body motion was controlled using the pneumatic drive system. In [14], input tracking of flexible manipulators using a PD, PID, ZVDD and a hybrid fuzzy control approach was investigated. LQR, LQR-PID, and hybrid LQR-Input shaping methods were proposed in [15] for hub angle control and residual vibration suppression of the flexible manipulator systems. A non-collocated PID and LQR controllers for vibration and input tracking control was Implemented in [16]. S. Deif et all [17] presented a tuned PD controller optimized using a modified genetic algorithm (GA) for vibration and input tracking control of flexible manipulator. Simulation studies in [18], demonstrated the capability of feedback linearization and input shaping control approach in the elimination of residual vibrations. The robust control technique was presented [19] and Research in [20] suggested a nonlinear adaptive predictive model controller for vibrations and position control of single-link flexible manipulator. Shape optimization of the revolute joint of a single-link flexible manipulator for suppression of vibrations was presented in [21]. Adaptive control of a single-link flexible manipulator using the sliding mode technique was presented [22], and Active control of a single-link flexible manipulator using nonlinear conventional motor was proposed in [23], and the two nonlinear controllers were presented for tip deflection suppression and hub angle tracking control of the system.

Owing to the presented literature there is still the need to increase the precision in hub angle positioning via a simple and cost-effective control scheme to achieve accurately and effectiveness of pick and place of an object in the industries. This paper proposed a novel hybrid control scheme, where output-based command shaping filter was incorporated with LMI control techniques for tip deflections suppression and precise hub angle control of single-link flexible manipulator. An output-based command filter was designed using the system output to suppress tip deflection while the LMI closed-loop control schemes were employed for hub angle tracking control and optimization. The system dynamics, controller design, and results and discussion are presented in Section 2, 3 and 4 respectively while Section 5 presented conclusions and future recommendation.

\section{SYSTEM DYNAMICS}

The single-link flexible manipulator system is as shown in Figure 1, whereas Figure 2 shows the schematic diagram of the system. The mathematical model representation of the system is obtained using the finite element method. The system comprises of a non-movable coordinate XOY and a movable coordinate POQ. And the applied torque at the hub is represented by $\tau(t)$. The parameters $M_{p}, \mathrm{~V}, \mathrm{E}, \mathrm{I}, \mathrm{P}$ and $I_{h}$ are manipulator payload, area moment of inertia, young modulus, mass density per unit volume, cross-sectional area and hub inertia respectively [24]. Table 1 shows the system parameters. The effects of rotary inertia and transverse shear are neglected as the system is long and slender and only moves in the XOY plane. Based on the aforementioned assumption, the Bernoulli-Euler beam theory is used in developing the model for the system's elastic behaviour. Moreover, the system is assumed to have a constant cross-sectional area, uniform material property, and continuous vibrations in the horizontal direction with negligible gravitational effect and experience torsion and is stiff in vertical bending. The single link manipulator system is made of aluminium material with dimension $900 \mathrm{~mm} \times 19.008 \mathrm{~mm} \times 3.2004 \mathrm{~mm}$ [25].

Table 1. System parameters [25]

\begin{tabular}{lccc}
\hline \multicolumn{1}{c}{ Parameters } & Symbols & Values & Units \\
\hline Young modulus & $E$ & $71 \times 10^{9}$ & $\mathrm{~N} / \mathrm{m}^{2}$ \\
Density per unit volume & $\rho$ & 2710 & $\mathrm{Kg} / \mathrm{m}^{3}$ \\
The second moment of inertia & $I$ & 5.1924 & $\mathrm{~m}^{4}$ \\
Flexible link length & $L$ & 0.96 & $m$ \\
Flexible link width & $W$ & 0.019 & $m$ \\
Flexible link thickness & $B$ & 0.003 & $m$ \\
Hub inertia & $I_{h}$ & $5.86 \times 10^{-4}$ & $\mathrm{Kgm}^{2}$ \\
Moment of inertia & $I_{b}$ & 5.1924 & $\mathrm{Kgm}^{2}$ \\
\hline
\end{tabular}

Indonesian J Elec Eng \& Comp Sci, Vol. 20, No. 1, October 2020 : 109 - 116 


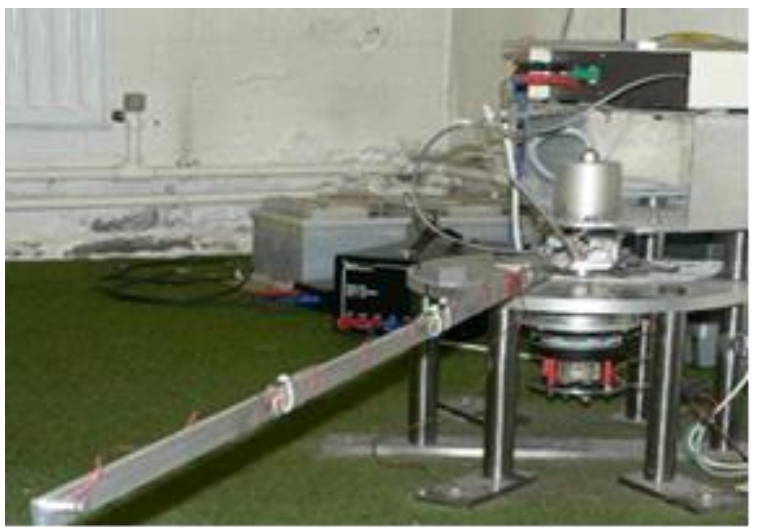

Figure 1. Experimental set up of the flexible arm

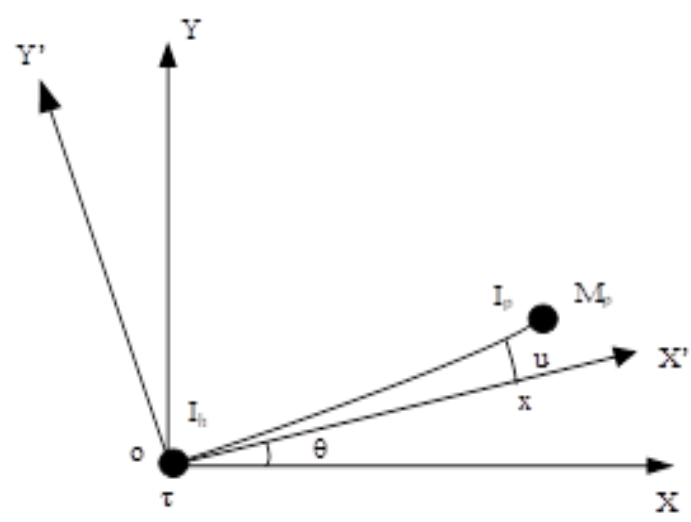

Figure 2. Schematic of the flexible arm

The single-link flexible manipulator model used in this work is as obtained in [8, 24], the mathematical model representation of the system is obtained using the finite element method. Hence the state-space model was obtained as;

$$
\begin{aligned}
& \dot{v}=A v+B u \\
& y=C v+D u
\end{aligned}
$$

Thus, the A, B, C, and D matrixes are obtained as;

$$
A=\left[\begin{array}{cccc}
0 & 0 & 1 & 0 \\
0 & 0 & 0 & 1 \\
0 & 58209 & 0 & -33 \\
0 & -38548 & 0 & -27
\end{array}\right] B=\left[\begin{array}{c}
0 \\
0 \\
1013.6 \\
-821.0
\end{array}\right] C=\left[\begin{array}{cccc}
1 & 0 & 0 & 0 \\
0 & 1 & 0 & 0
\end{array}\right] D=\left[\begin{array}{l}
0 \\
0
\end{array}\right] v=\left[\begin{array}{c}
\theta \\
\alpha \\
\dot{\theta} \\
\dot{\alpha}
\end{array}\right]
$$

The matrix $v$ represented the state variables, which are hub angle and tip deflection respectively and their derivatives.

\section{CONTROLLER DESIGN}

\subsection{Output-based command filter}

In this section, the output-based command filter was designed using the output of the single-link flexible manipulator. First, the reference system was designed based on the system dynamic response, and then system output was decomposed and measured using simulation. MATLAB codes formulated based on the mathematical model of the filter were used to obtain the filter gains. The basic principle of the outputbased command filter strategy is presented by using the second-order system as expressed by (3) [26, 27].

$$
G(s)=\frac{k w_{n}^{2}}{s^{2}+2 \xi w_{n} s+w_{n}^{2}}
$$

The reference system was set to be designed as;

$$
G_{r}(s)=\frac{k_{m} w_{m}^{2}}{s^{2}+2 \xi_{m} w_{m} s+w_{m}^{2}}
$$

Also, the filter can be designed as;

$$
F(s)=\frac{k_{m} w_{m}^{2} s^{2}+2 \xi w_{n} s+w_{m}^{2}}{k w_{n}^{2} s^{2}+2 \xi_{m} w_{m} s+w_{m}^{2}}
$$

Thus, Product of $\mathrm{G}(\mathrm{s})$ and $\mathrm{F}(\mathrm{s})$ will yield $\mathrm{G}_{r}(\mathrm{~s})$ based on the principle of pole-zero cancellation, and hence, by selecting $k_{m}, \xi_{m}, w_{m}$, adequate static gain, damping ratio, and bandwidth can be realized respectively [28].

\footnotetext{
Optimized output-based input shaping for control of single-link flexible manipulator... (Nura Musa Tahir)
} 
Hence;

$$
F(s)=\frac{a_{2} s^{2}+a_{1} s+a_{0}}{s^{2}+2 \xi_{m} w_{m} s+w_{m}^{2}}
$$

The purpose is to get the filter gains $\left(a_{0}, a_{1}, a_{2}\right)$ so that zeros $F(s)$ will cancel the identical poles of $G(s)$ [28]. The critically damped system is considered in designing a reference system which can be realized as;

$$
G_{r}(s)=\frac{w_{c}^{2}}{\left(s+w_{c}\right)^{2}}
$$

The parameter $w_{c}$, which is the system bandwidth, is carefully chosen based on the system time response. The goal of the design is to obtain accurate filter coefficients so that the system has zero or little vibration. The single-link flexible manipulator considered in this work is a type- 1 system, and therefore, $a_{0}$ is zero and the system is reduced to the fourth-order. Hence, the reference system was obtained as in (8) by selecting $w_{c}=10$ based on (7).

$$
G_{r}(s)=\frac{10^{6}}{s^{4}+40 s^{3}+600 s^{2}+4000 s+10^{6}}
$$

Thus, the filter gains were obtained by running the MATLAB code formulated based on the form;

$$
\left[\begin{array}{l}
a_{1} \\
a_{2} \\
a_{3} \\
a_{4}
\end{array}\right]=\left[\begin{array}{llll}
S_{11} & S_{12} & S_{13} & S_{14} \\
S_{21} & S_{22} & S_{23} & S_{24} \\
S_{31} & S_{32} & S_{33} & S_{34} \\
S_{41} & S_{42} & S_{43} & S_{44}
\end{array}\right]\left[\begin{array}{l}
S_{1 r} \\
S_{2 r} \\
S_{3 r} \\
S_{4 r}
\end{array}\right]
$$

Substituting the gains, the filter was obtained as;

$$
F(s)=\frac{0.7952 s^{4}+14.4578 s^{3}+484.7298 s^{2}+5.6805 \times 10^{3} s}{s^{4}+40 s^{3}+600 s^{2}+4000 s+10^{6}}
$$

\subsection{LMI controller design}

Stability and transient response of linear systems depend on the locations of the poles in the complex plane, the left half-plane as in Figure 3 is the stability region [29]. Consider a linear dynamic system;

$$
\dot{X}=A_{c} X
$$

The Lyapunov theorem states that the system in (10) is said to be asymptotically stable once a real symmetric matrix $P$ satisfies the following LMIs [29];

$$
A_{c} P+A_{c} A^{T}<0, \quad P=P^{T}>0
$$

The LMIs in (11) provides the conditions for the stability of the system in (10). The LMI region is as presented in Figure 4.

All the poles of the system in (10) will be lying in the LMI region of Figure 4 if and only if there exists asymmetrical positive definite matrix $P$ such that;

$$
\begin{aligned}
& A_{c} P+P A_{c}{ }^{T}+2 a P<0, \\
& A_{c} P+P A_{c}{ }^{T}+2 b P>0, \\
& {\left[\begin{array}{cc}
-r P & c P+P A_{c}{ }^{T} \\
c P+A_{c} P & -r P
\end{array}\right]<0, \quad P=P^{T}>0}
\end{aligned}
$$




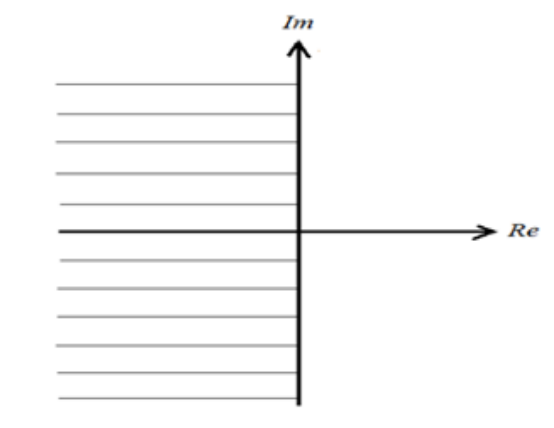

Figure 3. Left half-plane

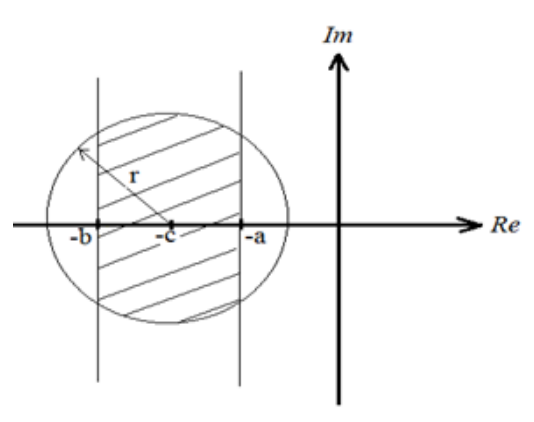

Figure 4. LMI region

The LMIs in (12) and (13) represent the vertical strip, while the LMI in (14) represents the circle centred at $(c, 0)$ with radius $r>0$. The controller gains $K$ and the reference input scaling factor $N$ were found as $[0.873,63.517,0.2389$, and 0.1649$]$ and $[0.873,63.517,0.2389,0.1649]$ respectively by using MATLAB codes. The complete closed-loop control scheme block diagram is as shown in Figure 5.

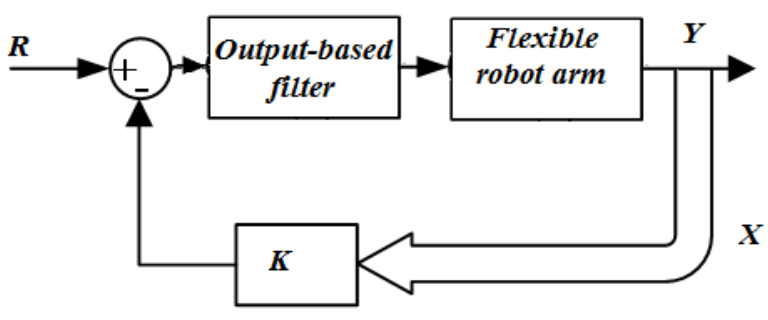

Figure 5. Block diagram of the closed-loop control scheme

\section{RESULTS AND ANALYSIS}

To precisely control the single-link flexible manipulator for set-point tracking, a bang-bang input torque was used as the reference angle. This evaluates the performance of the LMI-OBCS under various payloads for tip deflection suppression and tracking control. The simulation results of the proposed control schemes are presented in this section. The payload mass was changed from $0 \mathrm{~g}$ to $30 \mathrm{~g}$, and $50 \mathrm{~g}$ to test the robustness of the proposed novel hybrid control scheme to parameter variation. The optimized controller gains were obtained as; $K=[0.873,63.517,0.2389$, and 0.1649]. Figure 6 and Figure 7 show the tip deflection and hub angle under $0 g$ payload. Thus, it can be observed that tip deflections were suppressed and precise hub angle tracking was achieved. The maximum tip deflections of $2.20 \times 10-3 \mathrm{~m}$ and settling time and rise time of $1.3 \mathrm{sec}$ and $0.95 \mathrm{sec}$ respectively with zero steady-state error and zero overshoot were observed.

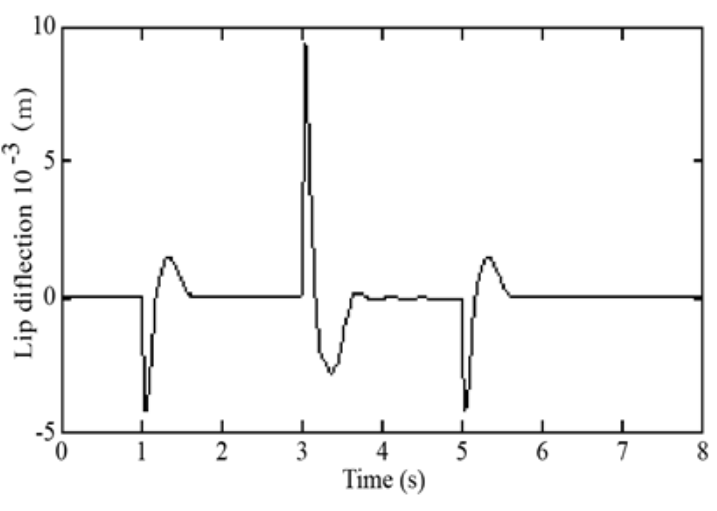

Figure 6. Tip deflection response to LMI-OBCS controller

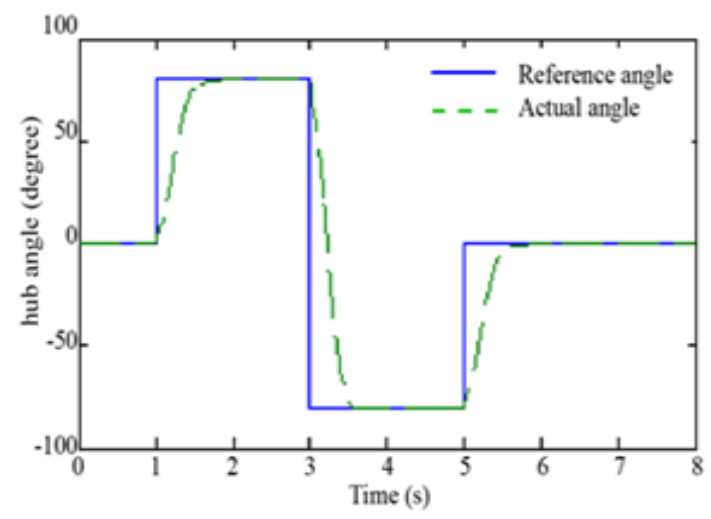

Figure 7. Hub angle response to LMI-OBCS

\footnotetext{
Optimized output-based input shaping for control of single-link flexible manipulator... (Nura Musa Tahir)
} 
This shows that the objectives of the control schemes were achieved. Also, the proposed control schemes were tested under various payloads mass as shown in Figure 8 and Figure 9. From these figures, it is clear that no significant changes were observed under various payloads. Thus, the tip deflections changes under $30 \mathrm{~g}$ from $2.20 \times 10^{-3} \mathrm{~m}$ to $3.3 \times 10^{-3} \mathrm{~m}$ and settling time and rise time from $1.3 \mathrm{sec}$ and $0.95 \mathrm{sec}$ to $1.25 \mathrm{sec}$ and $0.85 \mathrm{sec}$ respectively with no changes in steady-state error and overshoot.

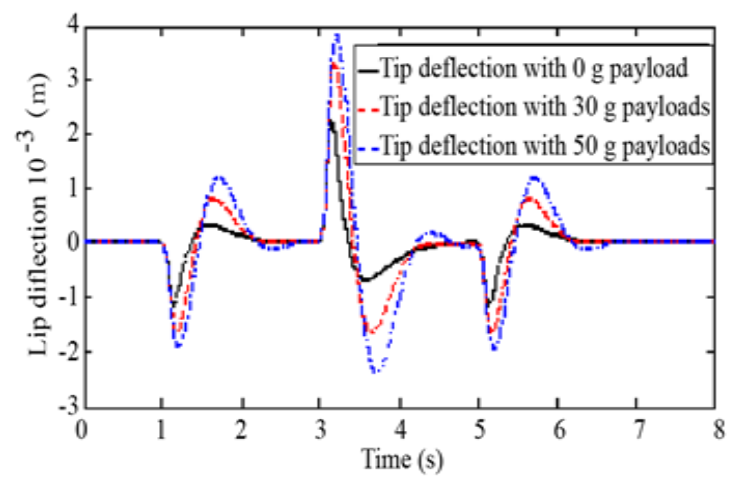

Figure 8. Tip deflection response to LMI-OBCS controller with payloads variation

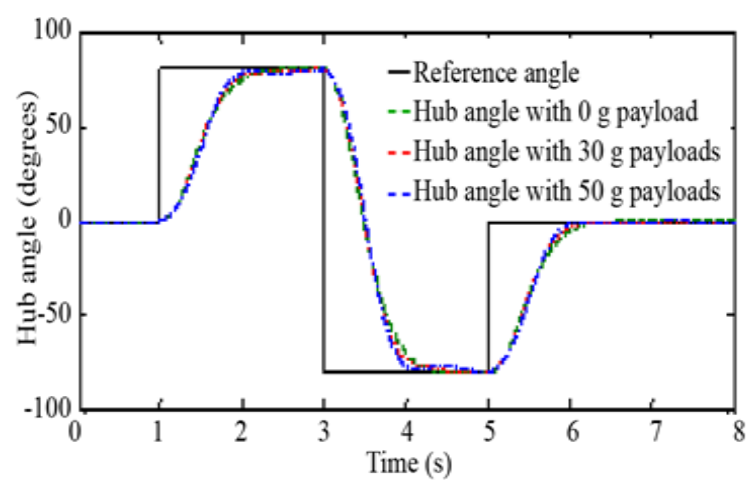

Figure 9. Hub angle response to LMI-OBCS controller with payloads variation

While under $50 \mathrm{~g}$ it changes from $2.20 \times 10^{-3} \mathrm{~m}$ to $3.9 \times 10^{-3} \mathrm{~m}$ and settling time and rise time from 1.3 sec and $0.95 \mathrm{sec}$ to $1.21 \mathrm{sec}$ and 0.82 respectively, also no changes were experienced in overshoot and steadystate error as showed in Figure 8, Figure 9 and Table 3. Moreover, IAE and ISE were used as the performance indexes of the proposed control schemes and based on the numerical values recorded in Table 2, the performances of the proposed novel hybrid control scheme is excellent as the less and negligible error was recorded.

Table 2. Performance indexes

\begin{tabular}{ccc}
\hline Payload Mas $(\mathrm{g})$ & IAE $(\mathrm{rad})$ & ISE $(\mathrm{rad})$ \\
\hline $0 \mathrm{~g}$ & $4.822 \times 10^{-7}$ & $5.012 \times 10^{-7}$ \\
$30 \mathrm{~g}$ & $5.45 \times 10^{-7}$ & $5.72 \times 10^{-7}$ \\
$50 \mathrm{~g}$ & $5.83 \times 10^{-7}$ & $6.145 \times 10^{-7}$ \\
\hline
\end{tabular}

Table 3. Time response analysis

\begin{tabular}{ccccc}
\hline Payload Mass $(\mathrm{g})$ & Max. Overshoot $(\%)$ & Settling Time $(\mathrm{s})$ & Rise Time $(\mathrm{s})$ & Tip Deflection $(\mathrm{m})$ \\
\hline $0 \mathrm{~g}$ & 0.00 & 1.3 & 0.95 & $2.2 \times 10^{-3}$ \\
$30 \mathrm{~g}$ & 0.00 & 1.25 & 0.85 & $3.3 \times 10^{-3}$ \\
$50 \mathrm{~g}$ & 0.00 & 1.21 & 0.82 & $3.9 \times 10^{-3}$ \\
\hline
\end{tabular}

\section{CONCLUSION}

In this paper, tip deflections and precise hub angle position control of single-link flexible manipulators have been proposed. An OBCS filter was designed using the output of the single-link flexible manipulator to suppress tip deflections and then LMI closed-loop control scheme was incorporated for precise hub angle tracking. The robustness of this hybrid control scheme was tested by changing the mass of the payload from $0 \mathrm{~g}, 30 \mathrm{~g}$, and 50g. The IAE, ISE, and TRA were used as the performance indexes. Based on the Simulation results, tip deflections and residual vibrations were well suppressed and precise hub angel positioning was achieved. The control schemes are robust to payload variation, hence recommended for realtime implementation.

\section{ACKNOWLEDGEMENTS}

The authors are grateful to Abubakar Tafawa Balewa University (ATBU) Bauchi and Bayero University Kano (BUK), Nigeria for providing financial support and research resources. 


\section{REFERENCES}

[1] C. T. Kiang, A. Spowage, and C. K. Yoong, "Review of Control and Sensor System of Flexible Manipulator," J. Intell. Robot. Syst., vol. 77, pp. 187-213, 2014.

[2] M. A. Ahmad, A. N. K. Nasir, N. S. Pakheri, N. M. A. B. D. Ghani, M. A. Zawawi, and N. H. Noordin, "Microcontroller-Based Input Shaping for Vibration Control of Flexible Manipulator System," Australian Journal of Basic and Applied Sciences, vol. 5, no. 6, pp. 597-610, 2011.

[3] M.Khairudin, Z Mohamed, and A.R. Husain, "Dynamic model and robust control of flexible link robot manipulator," TELKOMNIKA (Telecommunication, Computing, Electronics and Control), no. 2, pp. 1-9, 2011.

[4] D.H. Vu, S. Huang, and T.D. Tran, "Hierarchical robust fuzzy sliding mode control for a class of Simo underactuated systems with mismatched uncertainties," TELKOMNIKA (Telecommunication, Computing, Electronics and Control), no. 6, pp. 1-17, 2019.

[5] M. Khairudin, Z. Mohamed, and A.R. Husain, "System identification and LMI based robust PID control of a two-link flexible manipulator," TELKOMNIKA (Telecommunication, Computing, Electronics and Control), no. 4, pp. 1-12, 2014.

[6] Q. Zhang, J. K. Mills, W. L. Cleghorn, J. Jin, and Z. Sun, "Dynamic model and input shaping control of a flexible link parallel manipulator considering the exact boundary conditions," Robotica, vol. 33, no. 6, pp. 1201-1230, 2015.

[7] M. Romano, "Experiments on Command Shaping Control of a Manipulator with Flexible Links," IEEE Trans. Syst. Man Cybern. pp. 1-41, 2000.

[8] Z. Mohamed and M. O. Tokhi, "Vibration control of a single-link flexible manipulator," Syst. Control Eng., vol. 216, pp. 191-210, 2015.

[9] W. Singhose, "Command shaping for flexible systems: A review of the first 50 years," Int. J. Precis. Eng. Manuf., vol. 10, no. 4, pp. 153-168, 2009.

[10] N. M. Tahir, A.A. Bature, U. I. Bature, A.U, Sambo, and A.Y. Babawuro, "Vibration and Tracking Control of a Single-Link Flexible Manipulator Using LQR and Command Shaping," Journal of Multidisciplinary Engineering Science and Technology, vol. 3, pp. 45-67, 2016.

[11] Noordin A, "Simulation and Experimental Study on PID Control of a Quadrotor MAV with Perturbation," Bulletin of Electrical Engineering and Informatics, vol. 15, no. 5, pp.1- 9, 2020.

[12] N. M. Tahir, S. M. Hassan, Z. Mohamed, and A. G. Ibrahim, "Output-Based Input Shaping for Optimal Control of SingleLink Flexible Manipulator" International Journal on Smart Sensing and Intelligent Systems, vol. 10, pp. 367-386, 2017.

[13] Z. Qiu and Z. Zhao, "Pneumatic Drive Active Vibration Control for Flexible Manipulator Using an Adaptive Interactive PD Controller," Proceedings of the 2012 IEEE International Conference on Robotics and Biomimetics, pp. 1956-1961, 2012.

[14] M. Ashraf, M. Z. Mohd Tumari, and A. N. Nasruddin Nasir, "Composite Fuzzy Logic Control Approach to a Flexible Joint Manipulator," Int. J. Adv. Robot. Syst., pp.13- 1234, 2013.

[15] V. Feliu, F. J. Castillo, F. Ramos, and J. A. Somolinos, "Robust tip trajectory tracking of a very lightweight singlelink flexible arm in presence of large payload changes," Mechatronics, vol. 22, no.5, pp. 594-613, 2012.

[16] M. A. Ahmad and Z. Mohamed, "Modelling and simulation of vibration and input tracking control of a single-link flexible manipulator," Pertanika J. Sci. Technol., vol. 18, no. 1, pp. 61-76, 2010.

[17] S. Deif, M. Tawfik, and H. A. Kamal, "Vibration and Position Control of a Flexible Manipulator using a PD- tuned Controller with Modified Genetic Algorithm," Alexandria, vol. 15, pp. 15-17, 2011.

[18] L. Ke-Ping and L. Yuan-Chun, "Vibration Suppression for a Class of Flexible Manipulator Control with Input Shaping Technique," International Conference on Machine Learning and Cybernetics, Dalian China, pp. 835-839 Aug 2006.

[19] H. Alazki, P. Ordaz, and a Poznyak, "Robust bounded control for the flexible arm robot," 52nd IEEE Conference on Decision and Control, pp. 3061-3066. IEEE, 2013.

[20] A. K. Ravandi, E. Khanmirza, and K. Daneshjou, "Hybrid force/position control of robotic arms manipulating in uncertain environments based on adaptive fuzzy sliding mode control," Applied Soft Computing, vol. 70, no. 1, pp. 864-74, 2018.

[21] S. Mahto, "Shape optimization of the revolute-jointed single-link flexible manipulator for vibration suppression,' MAMT, vol. 75, pp. 150-160, 2014.

[22] R. Farah, M. Saad, and M. Saad, "Adaptive Control for a Single Flexible Link Manipulator Using Sliding Mode Technique," 2009 6th Int. Multi-Conference Syst. Signals, Devices, 2009.

[23] S. C. P. Gomes, V. S. da Rosa, and B. C. Albertini, "Active control to flexible manipulators," Mechatronics, IEEE/ASME Trans., vol. 11, no. 1, pp. 75-83, 2006.

[24] N. M. Tahir, "An Output-based Filter for Control of a Single-link Flexible Manipulator," Master Thesis, Universiti Teknologi Malaysia, 2015.

[25] N. M. Tahir, K. A. Abubakar, A. U. Sambo, A. B. Kunya, and I. Gambo, "Vibrations and intelligent tracking control of single-link flexible manipulator," Sensors Transducers, vol. 232, no 4, pp. 8-14, 2019.

[26] N. M. Tahir, K. A. Abubakar, A. U. Sambo, U. I. Bature, N. A Yakub, and L. Haliru, "Output-Based Input Shaping for Sway Control of a 3D Crane System," International Journal of Electrical and Electronics Engineering, vol. 11, pp. 28-34, 2016.

[27] N. M. Tahir, K. A. Abubakar, M. M. Jamil, K. B. Jahun, and F. S. Bala, "Comparative Analysis of Input Shaping Techniques for Sway Control of Nonlinear Crane System," International Journal of Electrical Engineering and Applied Sciences, vol. 1, no. 2, pp. 13-19, 2018.

[28] H. Liman, N. M. Tahir, G. Sani, E. C. Anene, and A. Y. Babawuro, "Comparative Studies of Hybrid Model-Dependent and Model-Free Controller Application on Crane System," Sensors and Transducers, vol. 230, no. 2, pp. 31-38, 2019.

[29] M. Mohammad, "Linear Matrix Inequality-Based State Feedback Control of a Gantry Crane System," Bayero Journal of Engineering and Technology, vol. 13, no. 2, pp. 107-115, 2018. 


\section{BIOGRAPHIES OF AUTHORS}
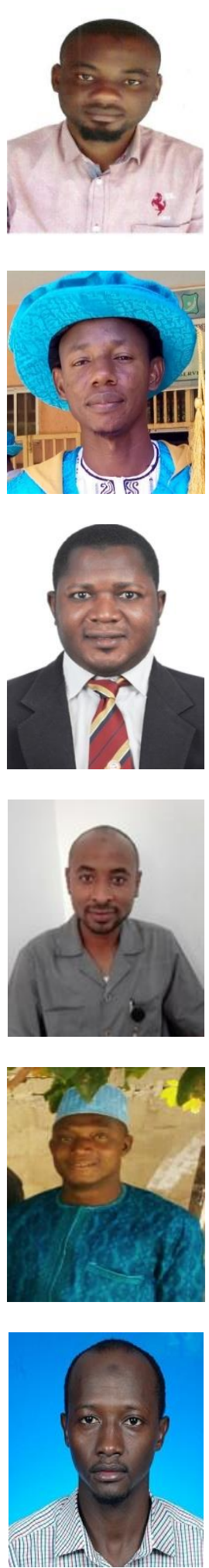

Nura Musa Tahir received the B.Eng. degree in Electrical Engineering from Bayero University, Kano in 2012 and M.Eng. Degree in Mechatronics and Automatic Control from the Universiti Teknologi Malaysia in 2016. He has been involved in research at Mechatronics systems and Robotics Laboratory in Universiti Teknologi Malaysia on vibration control, robotics and Mechatronics system design. He has been a lecturer at the Department of mechatronic and system Engineering, Abubakar Tafawa Balewa University, Bauchi Nigeria since 2014. His main research interests include Vibration Control, Mechatronics Systems Design, Control System Design and Robotics.

Mustapha Muhammad is currently an Associate Professor in the Department of Mechatronic Engineering Bayero University, Kano, Nigeria. He received his Bachelor of Engineering and Master of Engineering degrees from Bayero University, Kano, Nigeria in January 2001 and February 2007 respectively. He received his $\mathrm{PhD}$ in Electrical Engineering (Robotics) in March 2014 from Universiti Teknologi Malaysia. His research interest includes the areas of artificial neural networks, fuzzy modelling and control, intelligent control theories and robotics.

Bashir Bala Muhammad received a Bachelor Engineering degree in Electrical Engineering from Bayero University Kano, Nigeria in 2010, and a Master's degree in Mechatronics Engineering from Universiti Teknologi Malaysia (UTM), in 2015. He obtained a PhD in Mechanical Engineering at the School of Mechanical Engineering, Northwestern Polytechnical University, Xi'an, China, 2019. Research interest: Control Theory and Engineering, Mechatronics Engineering, System Identification and Estimation, System Modeling, Simulation and Control, and Vibration Control

Researchgate Weblink: https://www.researchgate.net/profile/Bashir_Muhammad5

Auwal Shehu Tijjani received the B.Eng. degree in Computer Engineering from Bayero University, Kano in 2012 and M.Eng. Degree (with distinction) in Electrical (Mechatronics and Automatic Control) from the Universiti Teknologi Malaysia in 2016. He has been involved in research at Center for Micro-nano mechatronics systems and Micro-nano robotics in Universiti Teknologi Malaysia on Piezoelectric actuator nano position control, Nano mechatronics system design for diseases diagnosis, control system design. He is currently a Lecturer in Computer Engineering at Baze University, Abuja. His main research interests include Micro-nano Mechatronics Systems Design, Control System Design and Robotics.

Haliru Liman received his B.Eng. Degree in Electrical/Computer Engineering from the Federal University of Technology, Minna, Nigeria in 2006 and M.Eng. Degree in Electronics Engineering from Abubakar Tafawa Balewa University, Bauchi, Nigeria in 2018. He is currently with Department of Electrical/ Electronic Engineering, Abubakar Tafawa Balewa University, Bauchi, Nigeria. His current research interest includes Modelling and Simulation of Dynamic Systems, Development and Control of Electric Drives System, System Identification and Estimation, Optimisation and Intelligent Control.

Aminu Yahaya Zimit graduated from Bayero university kano (Mechanical Engineering) in 2012, and later in 2015 went to Malaysia (University of Malaya) for his Masters (M.Eng Mechatronics Engineering) and completed in 2016. Zimit conducted, supervised and published research articles in his area of specialization (Automation, Control, and robotics). Currently, he works with Hafar Albatin University, Saudi Arabia, where he taught courses in Mechanics, thermodynamics, heat and mass transfer, computer-aided design and manufacturing, Robotics and automation. 